\title{
Micro-scale Mineralogy and Imaging Reveal Polymorph Variance in Microbially Precipitated Calcium Carbonate
}

\author{
Neerja Zambare ${ }^{1}$, Alice Dohnalkova ${ }^{1}$ and Robin Gerlach $^{2}$ \\ ${ }^{1}$ Pacific Northwest National Laboratory, United States, ${ }^{2}$ Montana State University, Bozeman, Montana, \\ United States
}

Ureolytic bacteria can raise the alkalinity and $\mathrm{pH}$ of their surrounding media through ureolysis. When dissolved calcium is present under such conditions, calcium carbonate $\left(\mathrm{CaCO}_{3}\right)$ can precipitate out of solution - a process called microbially induced calcium carbonate precipitation (MICP). Precipitates formed by MICP can be used in a variety of environmental applications such as sealing leakage pathways of geologically stored carbon dioxide and reducing the spread of heavy metal / radionuclide contaminants in groundwater. ${ }^{1}$

The micro-scale interactions between the bacteria and the minerals that they form influence the mineral crystallinity and polymorphism, which can have large-scale impacts on mineral stability as different polymorphs have different thermodynamic stabilities. For example, some organics are known to stabilize metastable $\mathrm{CaCO}_{3}$ phases (vaterite or aragonite), or even the non-crystalline pre-cursor, amorphous calcium carbonate (ACC) ${ }^{2}$ To understand the role of organics in polymorph selection, it is necessary to study MICP at the micro-scale where organic-mineral interactions can be visualized and characterized.

To investigate MICP at the micro-scale, we have developed a platform to first generate micro-scale precipitates, and then correlatively image them using a suite of microscopy and microanalysis techniques. Using droplet-based microfluidics, we facilitated MICP inside $25 \mu \mathrm{m}$ diameter microfluidic droplets initially containing single cells of Escherichia coli MJK2 (Fig 1a), a bacterial strain modified to produce urease. ${ }^{3}$ Precipitates formed via MICP by E. coli MJK2 in these confined micro-environments were analyzed in-situ using confocal laser scanning microscopy (CLSM) and Raman microspectroscopy, and ex-situ using scanning electron microscopy (SEM), focused ion beam scanning electron microscopy (FIBSEM) and energy dispersive spectroscopy (EDS).

Our data show that bacterial cells (gfp - green in Fig 1b) were often encapsulated in a sheath of precipitate (calcite autofluorescence - red in Fig 1b). ${ }^{4}$ Fig 2 shows a single precipitate collected from a droplet and visualized using TEM $(\mathrm{a}, \mathrm{c})$ and SEM $(\mathrm{b}, \mathrm{d})$, where tubular structures resembling bacteria are seen covered with precipitate. This material showed an atomic EDS signal indicative of calcium carbonate. EM images of cells covered with precipitate appear in literature, but our study was the first to visualize this non-destructively under hydrated conditions (Fig 1b). The autofluorescence of the precipitates indicated the presence of calcite ${ }^{5}$, while Raman analysis indicated the presence of vaterite. This suggested that the formed precipitates likely contained both of the calcium carbonate polymorphs.

Currently, we aim to determine spatial distribution of these polymorphs within a single micro-precipitate. This is done by using FIBSEM to prepare thin sections from a micro-precipitate, followed by a spatially resolved STEM / SAD analysis to identify polymorphs present. Additionally, TEM is employed to identify any differences in organic signatures on the mineral surfaces when bacteria are present or absent. Furthermore, bacteria-free ureolytic culture supernatant is subjected to a similar range of EM and mineralogical analyses to investigate the influence of bacteriaon polymorph. These studies contribute to the understanding of the role of organics in polymorph selection, which can be used as an engineering parameter in application environments to optimize a desired polymorph. 

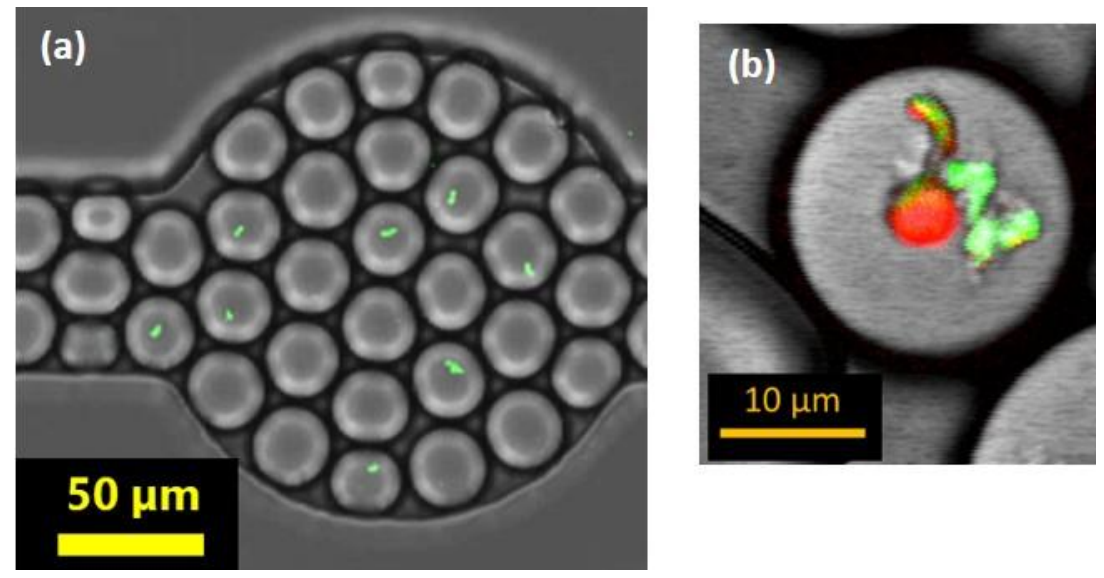

Figure 1. (a) A microfluidic device holding multiple droplets, some containing single cells of E. coli MJK2 (green). (b) Confocal Laser Scanning Microscopy image of a single microdroplet containing gfp-expressing bacteria (green) and precipitate formed via MICP (red, autofluorescence of calcite). The gfp signal can be seen co-locating with the red autofluorescence signal on one of the extensions from the central spherical precipitate.

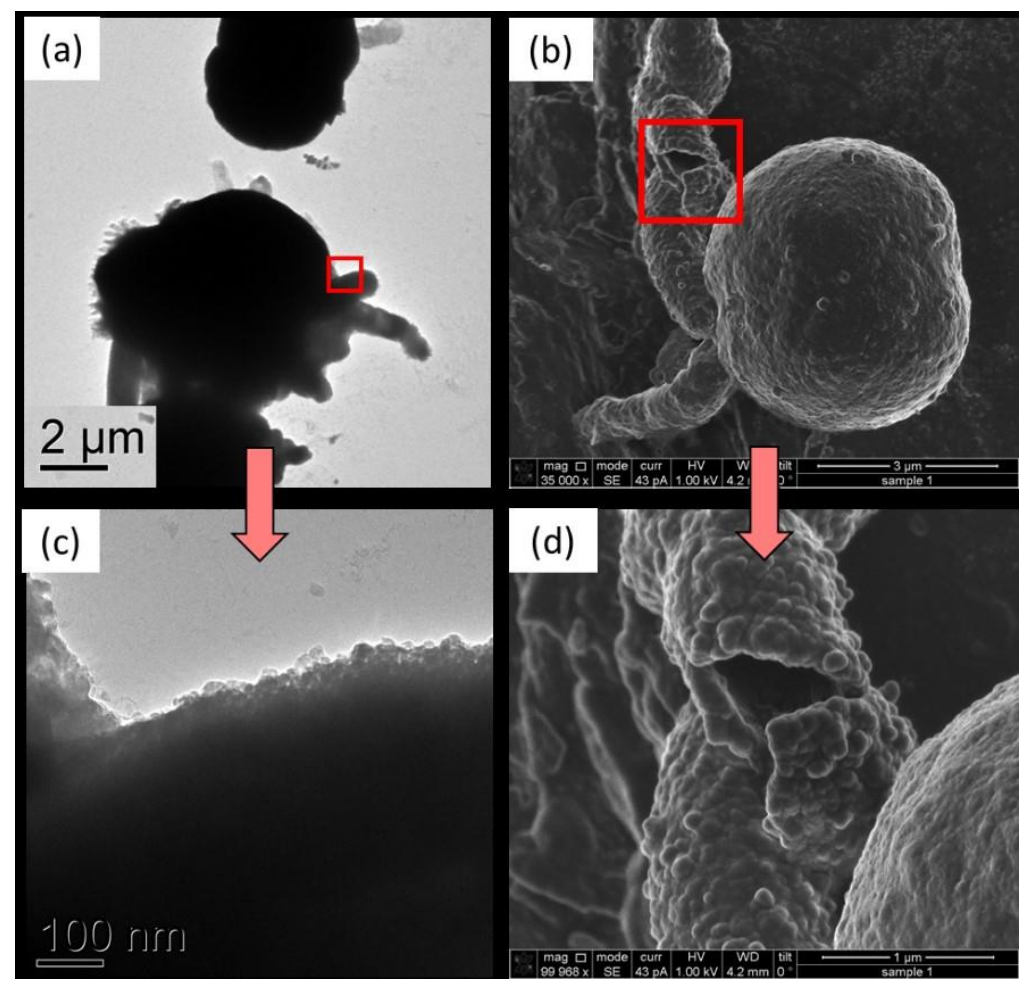

Figure 2. TEM (a) and SEM (b) image of a precipitate, similar to the spherical precipitate in Fig $1 \mathrm{~b}$, with magnified insets (c) - crystal-like structures on the bacteria-shaped extension on the precipitate and (d) bacterial-shaped sheath, respectively.

\section{References}


1. Phillips, A. J.; Gerlach, R.; Lauchnor, E.; Mitchell, A. C.; Cunningham, A. B.; Spangler, L., Engineered applications of ureolytic biomineralization: a review. Biofouling 2013, 29 (6), 715-33.

2. $\quad$ Bentov, S.; Weil, S.; Glazer, L.; Sagi, A.; Berman, A., Stabilization of amorphous calcium carbonate by phosphate rich organic matrix proteins and by single phosphoamino acids. Journal of Structural Biology 2010, 171 (2), 207-215.

3. Connolly, J.; Kaufman, M.; Rothman, A.; Gupta, R.; Redden, G.; Schuster, M.; Colwell, F.; Gerlach, R., Construction of two ureolytic model organisms for the study of microbially induced calcium carbonate precipitation. Journal of Microbiological Methods 2013, 94 (3), 290-299.

4. Zambare, N. M.; Naser, N. Y.; Gerlach, R.; Chang, C. B., Mineralogy of microbially induced calcium carbonate precipitates formed using single cell drop-based microfluidics. Scientific Reports 2020, 10 (1), 17535.

5. Yoshida, N.; Higashimura, E.; Saeki, Y., Catalytic Biomineralization of Fluorescent Calcite by the Thermophilic Bacterium Geobacillus thermoglucosidasius. Applied and Environmental Microbiology 2010, 76(21), 7322-7327. 